\title{
Linkage and association between HLA and 21-hydroxylase deficiency
}

\author{
PETER T KLOUDA, RODNEY HARRIS, AND DAVID A PRICE
}

From the Department of Medical Genetics, St Mary's Hospital, and the Royal Manchester Children's Hospital, Manchester

SUMMARY Congenital adrenal hyperplasia because of 21-hydroxylase deficiency is closely linked to the HLA system. The lod scores in 14 informative families are presented. Apart from linkage, the 21-hydroxylase deficiency is associated with an increase of BW47 antigen and lack of B8 antigen in patients. A family with a possible recombination between the 21-hydroxylase deficiency and the HLA complex was found, thus indicating that the 21-hydroxylase gene lies outside the HLA system and is closely linked to the HLA-DR locus.

Congenital adrenal hyperplasia (CAH) is an autosomal recessive disease which is most commonly caused by 21 -hydroxylase $(21-\mathrm{OH})$ deficiency. This deficiency results in decreased cortisol synthesis and secondary increased production of adrenocorticotrophic hormone (ACTH). In its turn, excess ACTH secretion leads to overproduction of adrenal androgens and consequent virilisation. The synthesis of aldosterone involves a 21-hydroxylase step and thus in some patients salt loss occurs in addition to virilisation. The reason why others are not salt losers and may have normal or high aldosterone levels ${ }^{1}$ is not well understood. The gene responsible for 21-OH deficiency has been shown to be closely linked to the HLA system, ${ }^{2}$ but it is not known whether this gene is structural or regulatory in type. We have confirmed this linkage. ${ }^{3}$ Since then, association between 21-OH deficiency and several HLA antigens has been reported. ${ }^{4-6}$ In the present report we describe the haplotypes of 14 families containing at least one affected child and one or more sibs. A further eight affected children have been HLA typed, making 22 unrelated 21-OH deficient children in all.

\section{Patients}

Fourteen families with both parents and either two affected sibs or one patient and at least one other sib, totalling 40 children, were HLA typed. Eight children with $\mathrm{CAH}$ whose complete families were not available were also HLA typed. Three families (No 12, 13, and 14) were from Pakistan and the rest Received for publication 10 December 1979 were English. In two families the parents were first cousins (families 4 and 12) and in one family (family 14) the parents were more distantly related. The patients in families $2,6,9$, and 11 were non-salt losers as were patients 16 and 18 . The rest were salt losers.

\section{HLA typing}

HLA typing was performed by the standard NIH two stage micro-lymphocytotoxicity test. One hundred and twelve well defined sera were used to identify most of the HLA-A and -B locus antigens. Splits of HLA-A9 (W23, W24) or of B12 (W44, W45) were not tested for and the HLA-C locus antigens were identified in some subjects only. Monospecific antisera were not available for the BW47 antigen which was detected by a pattern of extra reactions in six antisera mainly for the B7 and B40 cross-reacting groups. Using these sera, BW47 could be detected with confidence in the presence of any other B locus antigen.

\section{Biochemistry}

Serum 17-hydroxyprogesterone levels were measured after ether extraction by radioimmunoassay (tritiated hormone supplied by the Radio Chemical Centre, Amersham, and antibodies by Steranti Research Ltd). Samples were taken at zero time and at 30 minutes after $250 \mathrm{mg}$ synacthen had been given intravenously. Urinary $5 \beta$-pregnane- $3 \alpha, 17 \alpha, 20 \alpha$ triol levels were measured using a modification of the method of Bell and Varley. ${ }^{7}$ The normal range 
for adult males is up to $6 \mathrm{nmol} / 24 \mathrm{~h}$ and the normal range for prepubertal boys aged 5 to 7 years is 0.6 to $1 \mathrm{nmol} / 24 \mathrm{~h}$. The normal range at 30 minutes for normal prepubertal boys is less than $10 \mathrm{nmol} / \mathrm{l}$ (established locally $\mathrm{n}=10$ ).

\section{Results}

Table 1 shows the HLA-A and -B genotypes of 14 families with two or more children which were used for linkage analysis (table 2). The HLA phenotypes of a further eight children with $\mathrm{CAH}$ for whom complete families were not available or who were

TABLE 1 HLA-A and-B genotypes in 14 families with $\mathrm{CAH}$

\begin{tabular}{|c|c|c|c|}
\hline $\begin{array}{l}\text { Family } \\
\text { No }\end{array}$ & Parents & $\begin{array}{l}\text { HLA } \\
\text { haplotypes }\end{array}$ & $\begin{array}{l}\text { Children's } \\
\text { HLA } \\
\text { haplotypes }\end{array}$ \\
\hline 1 & $\begin{array}{l}\text { F: A3, B7/A2, BW35 } \\
\text { M: A3, B14/A2, B5 }\end{array}$ & $\begin{array}{l}a / b \\
c / d\end{array}$ & $a / c * b / c$ \\
\hline 2 & $\begin{array}{l}\text { F: A2, B17/A1, B15 } \\
\text { M:AW26, B18/A9, B12 }\end{array}$ & $\begin{array}{l}a / b \\
c / d\end{array}$ & $\begin{array}{l}a / c^{+} a / d b / c \\
a / d ~ b / c a / c^{*}\end{array}$ \\
\hline 3 & $\begin{array}{l}\text { F: A3, BW47/A2, B12 } \\
\text { M:A3, BW47/A?, B7 }\end{array}$ & $\begin{array}{l}\mathbf{a} / \mathbf{b} \\
\mathbf{c} / \mathbf{d}\end{array}$ & $a / c^{*} a / c^{*}$ \\
\hline $4(C)$ & $\begin{array}{l}\text { F: A9, B7/A3, B12 } \\
\text { M: A9,B7/A2, B12 }\end{array}$ & $\begin{array}{l}a / b \\
a / c\end{array}$ & $a / a * b / c$ \\
\hline 5 & $\begin{array}{l}\text { F: A3, B40/A11, B7 } \\
\text { M: A3, B40/A29, B7 }\end{array}$ & $\begin{array}{l}a / b \\
c / d\end{array}$ & $\mathrm{~b} / \mathrm{d} \mathbf{a} / \mathrm{c}^{*} \mathrm{a} / \mathrm{c}$ \\
\hline 6 & $\begin{array}{l}\text { F: A11, BW22/A11, B27 } \\
\text { M:A3, B40/A2, B17 }\end{array}$ & $\begin{array}{l}a / b \\
c / d\end{array}$ & $a / c * b / d$ \\
\hline 7 & $\begin{array}{l}\text { F: A2, BW35/A ?, B8 } \\
\text { M:A1, B15/A11, B5 }\end{array}$ & $\begin{array}{l}a / b \\
c / d\end{array}$ & $\mathrm{~b} / \mathrm{c} \mathbf{a} / \mathrm{c}^{*}$ \\
\hline 8 & $\begin{array}{l}\text { F: A3. BW47/A1, B7 } \\
\text { M: A3, B22/A?, BW47 }\end{array}$ & $\begin{array}{l}a / b \\
c / d\end{array}$ & $a / d a / c a / c^{*}$ \\
\hline 9 & $\begin{array}{l}\text { F: A2, BW35/A29, BX } \\
\text { M: A2, B12/A1, B8 }\end{array}$ & $\begin{array}{l}a / b \\
c / d\end{array}$ & $a / c * b / d$ \\
\hline 10 & $\begin{array}{l}\text { F: A1, BW47/AW32, B14 } \\
\text { M: A29, B12/A2, B15 }\end{array}$ & $\begin{array}{l}a / b \\
c / d\end{array}$ & $a / c^{*} a / c^{*}$ \\
\hline 11 & $\begin{array}{l}\text { F: A26, B27/A1, B8 } \\
\text { M: A3, B7/A9, B12 }\end{array}$ & $\begin{array}{l}a / b \\
c / d\end{array}$ & $a / d a / c^{*}$ \\
\hline 12 (C P) & $\begin{array}{l}\text { F: A1, B5/AW25, B40 } \\
\text { M: A1, B5/A11, BW35 }\end{array}$ & $\begin{array}{l}a / b \\
a / c\end{array}$ & $\begin{array}{l}b / c b / c b / a \\
a / a x c a / c^{*}\end{array}$ \\
\hline & $\begin{array}{l}\text { F: A9, BX/A11, B40 } \\
\text { M: A9, BW35/A1, B17 }\end{array}$ & $\begin{array}{l}a / b \\
c / d\end{array}$ & $a / c^{*} a / c^{*}$ \\
\hline 14 (C P) & $\begin{array}{l}\mathrm{F}: \mathrm{A} 2, \mathrm{~B} 12 / \mathrm{A} ?, \mathrm{~B} 15 \\
\mathrm{M}: \mathrm{A} 2, \mathrm{~B} 12 / \mathrm{A} 11, \mathrm{~B} ?\end{array}$ & $\begin{array}{l}\mathbf{a} / \mathbf{b} \\
\mathbf{c} / \mathbf{d}\end{array}$ & $\begin{array}{l}a / c^{*} b / c a / d \\
a / d a / d\end{array}$ \\
\hline
\end{tabular}

C. consanguineous marriage;

$F$, father;

M, mother;

*, affected sib;

+, 21-OH deficiency homozygote, clinically 'normal';

$\mathbf{X}$, unknown antigen;

?, possible homozygosity or unknown antigens;

P, Pakistani families.
TABLE $3 H L A-A$ and $-B$ antigens in 8 patients

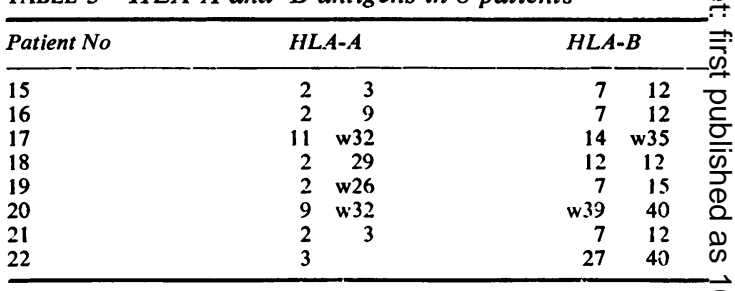

only children are given in table 3 . In families 4 and 12 the parents were first cousins sharing one HLAO haplotype, for which the affected children wereHLA homozygous. The patients in family 14 were also related in that the father's grandmother was aw first cousin of the mother's father. The parents had one haplotype HLA-A2, B12 in common and the affected child was found to be a HLA-A2, B12 homozygote. However, this haplotype is foundo fairly frequently in Pakistanis, and in the absence of other HLA typed relatives one cannot be certain that the HLA-A2, B12 haplotypes originated from aro common ancestor. Family 2 was ascertained througho a 5-year-old girl with CAH. HLA typing showed that she and her oldest brother were HLA identical.o The brother, a 23-year-old man, was later found tobe 21-OH deficient on both clinical and biochemicap grounds (table 4). In the Pakistani family No 120 (table 5), a maternal recombinant was observed. Aso previously noted, the parents were first cousins and $\overrightarrow{0}$ the affected child was HLA homozygous. Sib 4 carries a maternal HLA-A/CB recombinant haplo? type while inheriting the same paternal haplotype. as the affected sib. The two sibs are identical at the HLA-A locus but different at the $B$ and $C$ loc 0 indicating that the gene for $\mathrm{CAH}$ segregated with HLA-C, B and that sib 4 'escaped' 21-OH deficiency, through an intra-HLA recombination resulting ing the 'new' haplotype HLA-A1, CW4, BW35.

In family 8 a clinically completely normal sib was found to be HLA identical to the patient with CAHB Biochemical studies in the HLA identical brother of the patient with severe salt losing $\mathrm{CAH}$ were con $\mathrm{N}$ sistent with the carrier state, ${ }^{89}$ but totally incon sistent with the homozygous state (table 4). Detail of the HLA typing of the family together with othew

TABLE 2 Sum of lod scores for linkage between $H L A-B$ locus and 21-OH deficiency in 14 families

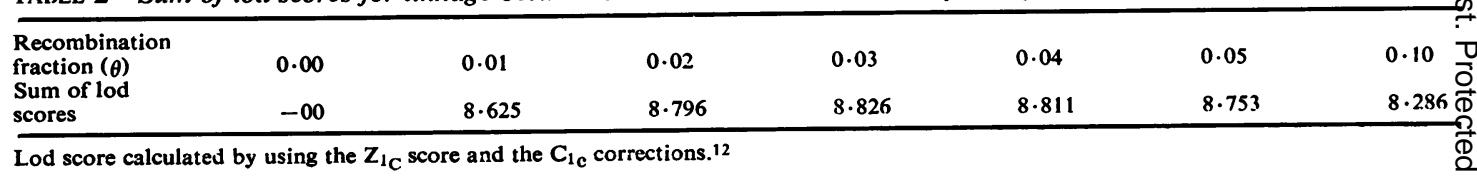

Lod score calculated by using the $\mathrm{Z}_{1_{\mathrm{C}}}$ score and the $\mathrm{C}_{1_{\mathrm{c}}}$ corrections. ${ }^{12}$ 
TABLE 4 Biochemical values in members of 2 families

\begin{tabular}{|c|c|c|c|c|c|}
\hline Family No & $S i b N o$ & Sex & $\begin{array}{l}\text { Urinary } \\
\text { pregnanetriol } \\
(\mu \mathrm{mol} / 24 \mathrm{~h})\end{array}$ & $\begin{array}{l}\text { Ser } \\
\text { afte } \\
O^{\prime}\end{array}$ & $\begin{array}{l}\text { erone } \\
\text { njection } \\
30^{\prime}\end{array}$ \\
\hline $\begin{array}{l}2 \\
8 \\
8\end{array}$ & $\begin{array}{l}5 \\
1 \\
2\end{array}$ & $\begin{array}{l}\mathbf{M} \\
\mathbf{M} \\
\mathbf{M}\end{array}$ & $\begin{array}{l}55 \\
0 \cdot 6 \\
2 \cdot 1\end{array}$ & $\begin{array}{r}70 \\
6 \\
7\end{array}$ & $\begin{array}{r}550 \\
7 \\
28\end{array}$ \\
\hline
\end{tabular}

TABle 5 A Pakistani family (No 12) with an intra $H L A$ recombination

\begin{tabular}{llll}
\hline Father & HLA-A1, B5 & /AW25, B40 CW2 & a/b \\
Mother & HLA-A1, B5 & IA11, BW35, CW4 & a/c \\
Sib 1 & HLA-AW25, B40, CW2 & /A11, BW35, CW4 & b/c \\
Sib 2 & HLA-AW25, B40, CW2 & /A11, BW35, CW4 & b/c \\
Sib 3 & HLA-AW25, B40, CW2 & /A1, B5 & b/a \\
Sib 4 & HLA-A1, B5 & /A1, BW35, CW4 & a/a-c \\
Patient & HLA-A1, B5 & /A1, B5 & a/a \\
\hline
\end{tabular}

genetic markers linked to the HLA system are given in table 6. Assuming only one recombination event between HLA and the 21-OH gene it appears that the 21-OH deficiency gene is carried in the father on the same chromosome as HLA-A1,B7,DRW2 (haplotype b), and in the mother on the chromosome coding for HLA antigens (A3),BW22,CW3,DRW6 (haplotype c). A paternal recombination between HLA-A,B,C, DR complex, and the 21-OH gene resulted in the 21-OH deficiency gene being coupled with the HLA haplotype A3,BW47,DRW7 in the patient. Thus, the 21-OH gene appears to be closely linked to the HLA-DR locus but outside the HLA complex. Unfortunately, other genetic markers were not informative.

The frequencies of HLA-A and -B antigens in the 22 unrelated patients and 230 controls are shown in table 7. No HLA-B8 positive patients were found although the HLA-B8 antigen is present in three of the families. The absence of HLA-B8 in CAH patients is statistically significant $(p=0.001$, Fisher's exact method) and remains significant after correction for the number of antigens tested $(\mathrm{p}=$ $0 \cdot 03)$. The decrease of HLA-A1 among the patients ( $\mathrm{p}=0.035$, uncorrected) is secondary as a result
TABLE 7 Frequencies of $H L A$ antigens in 22 patients and 230 controls

\begin{tabular}{|c|c|c|c|c|c|}
\hline$H L A$ & $\begin{array}{l}\text { Patients } \\
\text { No }\end{array}$ & $\%$ & $\begin{array}{l}\text { Controls } \\
\text { No }\end{array}$ & $\%$ & Probability* \\
\hline A1 & 3 & $13 \cdot 6$ & 79 & $34 \cdot 4$ & 0.0349 \\
\hline 2 & 9 & $40 \cdot 9$ & 112 & $48 \cdot 7$ & NS \\
\hline 3 & 9 & $40 \cdot 9$ & 70 & $30 \cdot 4$ & NS \\
\hline 9 & 3 & $13 \cdot 6$ & 39 & $17 \cdot 0$ & NS \\
\hline 10 & 3 & 13.6 & 18 & $7 \cdot 8$ & NS \\
\hline 11 & 2 & $9 \cdot 1$ & 32 & $13 \cdot 9$ & NS \\
\hline 28 & - & 0 & 17 & $7 \cdot 4$ & NS \\
\hline 19 & 4 & $18 \cdot 2$ & 43 & $18 \cdot 7$ & NS \\
\hline 29 & 2 & $9 \cdot 1$ & 11 & $4 \cdot 8$ & NS \\
\hline W30 & - & 0 & 9 & $3 \cdot 9$ & NS \\
\hline W31 & - & 0 & 6 & $2 \cdot 6$ & NS \\
\hline W32 & 2 & $9 \cdot 1$ & 11 & $4 \cdot 8$ & NS \\
\hline W33 & - & 0 & 6 & $2 \cdot 6$ & NS \\
\hline B5 & 1 & $4 \cdot 5$ & 12 & $5 \cdot 2$ & NS \\
\hline 7 & 7 & $31 \cdot 8$ & 61 & $26 \cdot 5$ & NS \\
\hline 8 & - & 0 & 65 & $28 \cdot 3$ & 0.0010 \\
\hline 12 & 7 & $31 \cdot 8$ & 79 & $34 \cdot 4$ & NS \\
\hline 13 & - & 0 & 14 & $6 \cdot 1$ & NS \\
\hline 14 & 2 & $9 \cdot 1$ & 21 & $9 \cdot 1$ & NS \\
\hline 15 & 2 & $9 \cdot 1$ & 20 & $8 \cdot 7$ & NS \\
\hline 16 & 1 & $4 \cdot 5$ & 7 & $3 \cdot 0$ & NS \\
\hline 17 & 1 & $4 \cdot 5$ & 27 & $11 \cdot 7$ & NS \\
\hline 18 & 1 & $4 \cdot 5$ & 13 & $5 \cdot 7$ & NS \\
\hline W21 & - & 0 & 4 & $1 \cdot 7$ & NS \\
\hline W22 & 2 & $9 \cdot 1$ & 9 & 3.9 & NS \\
\hline 27 : & 2 & $9 \cdot 1$ & 16 & $7 \cdot 0$ & NS \\
\hline W35 & 4 & $18 \cdot 2$ & 34 & $14 \cdot 8$ & NS \\
\hline 37 & - & 0 & 9 & $3 \cdot 9$ & NS \\
\hline 40 & 4 & $18 \cdot 2$ & 29 & $12 \cdot 6$ & NS \\
\hline W41 & - & 0 & 2 & 0.9 & NS \\
\hline W47 & 3 & $13 \cdot 6$ & 1 & 0.4 & 0.0022 \\
\hline
\end{tabular}

*Fisher's exact probability (one-sided)- uncorrected for number of observations.

NS, non-significant.

of linkage disequilibrium between HLA-A1 and B8. Three patients were found to be BW47 positive; one of these in family 3 is a BW47 homozygote. The increase of $\mathrm{BW} 47$ in patients with $\mathrm{CAH}$ is

TABLE $6 H L A$ and chromosome 6 markers in family 8

\begin{tabular}{|c|c|c|c|c|c|c|}
\hline & Biochemistry & HLA haplotypes & & $B f$ & Glo & $C 2$ \\
\hline $\begin{array}{l}\text { Father } \\
\text { Mother } \\
\text { Brother } \\
\text { Brother } \\
\text { Patient }\end{array}$ & $\begin{array}{l}\text { NT } \\
\text { NT } \\
\text { Normal } \\
\text { Carrier } \\
21-O H \text { deficiency }\end{array}$ & $\begin{array}{l}\text { A3, BW47,DRW7/A1, B7, DRW2 } \\
\text { (A3),BW22,CW3,DRW6/(A3),BW47,DRW4 } \\
\text { A3, BW47,DRW7/(A3),BW47,DRW4 } \\
\text { A3, BW47,DRW7/(A3),BW22,CW3,DRW6 } \\
\text { A3, BW47,DRW7/(A3),BW22,CW3,DRW6 }\end{array}$ & $\begin{array}{l}a / b \\
c / d \\
a / d \\
a / c \\
a / c\end{array}$ & $\begin{array}{l}\text { F,S } \\
\text { F,S } \\
\text { F,F } \\
\text { F,S } \\
\text { F,S }\end{array}$ & $\begin{array}{l}1 \\
2 \\
1,2 \\
1,2 \\
1,2\end{array}$ & $\begin{array}{l}1 \\
1 \\
1 \\
1 \\
1\end{array}$ \\
\hline
\end{tabular}

NT, not tested;

$\mathrm{Bf}$, properdin factor $\mathrm{B}$;

Glo, glyoxalase;

C2, C2 component of complement 
significant before correction $(p=0.002)$. As mentioned earlier, in family 8 the patient has become BW47 positive as a result of an apparent paternal recombination. This patient has a normal brother who is a BW47 homozygote.

\section{Discussion}

Our study confirms close genetic linkage between the HLA system and 21-OH deficiency, as originally reported by Dupont et al. ${ }^{2}$ Both Dupont and we have described recombinants showing that the 21-OH gene segregates with the HLA-B locus. In the present report, we describe a further probable recombinant, this time between the HLA complex as a whole and 21-OH. The family in which the proband has severe salt losing congenital adrenal hyperplasia was HLA typed on three separate occasions with indentical results. The sib who is HLA identical to the proband was clinically completely normal, and while the biochemical results were consistent with the carrier state, ${ }^{89}$ they were totally inconsistent with those of an affected homozygote. No other similar recombinations have been reported and it appears that $21-\mathrm{OH}$ is closely linked to the HLA and DR locus. The highest lod scores calculated for the linkage between HLA-B and the 21-OH deficiency gene in 14 informative families is obtained for $\theta=0.03$. Close linkage has been further confirmed by families in which the parents of an affected child share an HLA haplotype and the affected child or children are HLA homozygous. The linkage between HLA and 21-OH deficiency has been found both in Caucasian and Pakistani families and in salt losing and salt sparing types. The gene for CAH seems, from our data, to be outside the HLA complex and in linkage disequilibrium with HLA BW47 and B8.

The increased frequency of HLA-B47 in CAH has now been described independently by two groups. $^{56}$ The significant absence of HLA-B8 among 22 children in our study cannot be explained, but it may be postulated that HLA-B8 is in linkage disequilibrium with another gene which is either lethal in 21-OH homozygotes or completely compensatory. It is noteworthy that a decrease of HLA-B8 is present in most reports published so far (Svejgaard, 1978, personal communication).

The close linkage between HLA and CAH is relevant to both pre- and postnatal diagnosis. For example, we report in family 2 the identification of a previously unsuspected affected male by means of HLA typing. It is now possible to HLA type amniotic cells obtained by amniocentesis in the second trimester. ${ }^{10}$ Although amniotic fluid 17- hydroxyprogesterone assay is quicker and easier HLA typing will help to confirm or exclude the diagnosis of 21-OH deficiency in a fetus in a family? in which $\mathrm{CAH}$ has already occurred. ${ }^{11}$ Opinions will differ as to whether selective termination of $a \bar{D}$ fetus with 21-OH deficiency is justified in view of the wide variability of clinical manifestation and the relative effectiveness of treatment of affected subs jects. However, HLA typing in the second trimester may permit some degree of intrauterine treatmene of $\mathrm{CAH}$, although by this stage of gestation genita $\vec{F}$ differentiation is far advanced. HLA typing on amniotic cells in the third trimester, or of cord blood lymphocytes, can supplement biochemical diagnosis allowing early diagnosis and treatment of homozy gote 21-OH deficients in families in which one caser has already occurred. With further experience HLA typing may be shown to be a reliable way of distinguishing missed cases, carriers, and normaP subjects, although at present these distinctions are subject to a small error attributable to genetie recombination.

The assistance of Dr G M Eddison and the staff of $\overrightarrow{0}$ the biochemical laboratory of the Royal Man? chester Children's Hospital is gratefully acknowø ledged.

\section{References}

1 Kowarski AA. Mechanism of salt loss in congenita $\overrightarrow{\vec{B}}$ virilising adrenal hyperplasia. In: Lee PA et al, eds Congenital adrenal hyperplasia. Baltimore: University Park Press, 1977.

2 Dupont B, Oberfield SE, Smithwick EM, Lee TD:Levine LS. Close genetic linkage between HLA and congenital adrenal hyperplasia (21-hydroxylase dec ficiency). Lancet 1977; ii:1309-12.

3 Price DA, Klouda PT, Harris R. HLA and congenitaB adrenal hyperplasia linkage confirmed. Lancet 1978 ; 930-1.

4 Zappacosta S, de Felice M, Minozzi M, Lombardi G, Valentine R, Vanacote G. HLA and congenital adrenab hyperplasia. Lancet 1978 ;ii:24.

5 Klouda PT, Harris R, Price DA. HLA and congenita adrenal hyperplasia. Lancet 1978 ;ii:1046.

6 Pucholt V, Fitzsimmons JS, Gelsthorpe K, Pratt RF ̃̄ Doughty RW. HLA and congenital adrenal hyperplasia. Lancet 1978 ;ii :1046-7.

7 Bell M, Varley $\mathbf{H}$. The estimation of pregnanetriol and 17 hydroxy pregnanolone in urine in congenital adrenakw hyperplasia. Clin Chim Acta 1960;5:396-405.

8 Knorr D, Bidlingmayer F, Butenandt O, van Schnakenburg K, Wagner W. Test for heterozygosity of congenitaE adrenal hyperplasia. In: Lee PA et al, eds. Congenitate adrenal hyperplasia. Baltimore: University Park Press,-1977.

- Gutai JP, Kowarski AA, Migeon CJ. Detection ofo heterozygote carriers for congenital virilising adrenalD hyperplasia. In: Lee PA et al, eds. Congenital adrenaf hyperplasia. Baltimore: University Park Press, 1977. 
10 Niazi M, Coleman DV, Mowbray JF, Blunt S. Tissue typing amniotic fluid cells: potential use for detection of contaminating maternal cells. J Med Genet 1979;16:21-3.

11 Pollack MS, Levine LS, Pang S, et al. Prenatal diagnosis of congenital adrenal hyperplasia (21-hydroxylase deficiency) by HLA typing. Lancet $1979 ; \mathbf{i}: 1107-8$.

12 Smith CAB. Linkage scores and corrections in simple two- and three-generation families. Ann Hum Genet 1968; $32: 127-50$.

Requests for reprints to Dr Peter Klouda, Department of Medical Genetics, St Mary's Hospital, Hathersage Road, Manchester M13 0JH. 